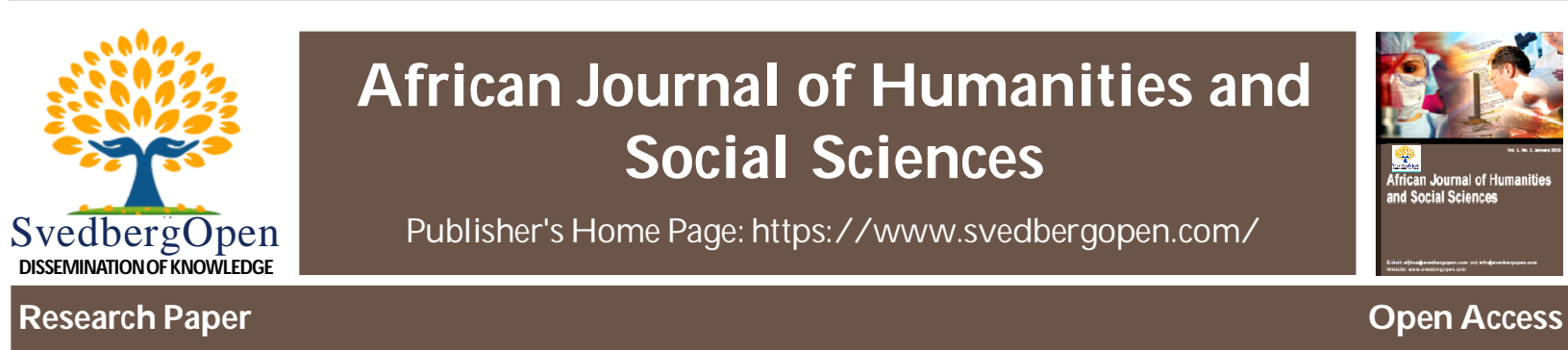

\title{
Opportunities and Challenges to Interculturality in the Digital Milieu
}

\author{
Anthony Le Duc ${ }^{1 *}$
}

'Executive Director, Asian Research Center for Religion and Social Communication, St. John's University, Thailand. E-mail: leducsvd.arc@gmail.com

Article Info

Volume 2, Issue 1, February 2022

Received : 15 March 2021

Accepted : 25 December 2021

Published : 01 February 2022

doi: 10.51483/AFJHSS.1.2.2022.18-29

\begin{abstract}
Interculturality has become an important sociological and missiological paradigm in recent years as a way to rectify shortcomings in how issues pertaining to culture have been addressed by social and religious institutions. As this paradigm aims for ideals such as reciprocity, respect, appreciation and mutuality in terms of how people from different cultures engage with each other, this paper sets out to examine whether interculturality characterized by these ideals can be achieved in the contemporary digital milieu. The paper argues that the present digital age with extensive use of Information and Communication Technology (ICT) can present both opportunities and challenges to promoting interculturality. The paper sets out to: (1) briefly present the concept of interculturality as understood by scholars in the Church today; (2) explore a number of opportunities and challenges to interculturality in the present digital milieu; and (3) proposes how interculturality can be advanced with the support of ICT. The thesis is that the work of achieving interculturality has to be actively carried out, using means of communication available in modern society. In the digital age, traditional ways of communication alone will not be effective in the face of many challenges to interculturality coming from present directions in development and use of ICT.

Keywords: Interculturality, Intercultural, ICT, Communication technology

(C) 2022 Anthony Le Duc. This is an open access article under the CC BY license (https: //creativecommons.org/licenses/by/4.0/), which permits unrestricted use, distribution, and reproduction in any medium, provided you give appropriate credit to the original author(s) and the source, provide a link to the Creative Commons license, and indicate if changes were made.
\end{abstract}

\section{Introduction}

Interculturality is a concept that has gained increasing significance as peoples and nations open themselves up to one another, especially with the ongoing phenomenon of globalization, which is accelerated by international migration and the rapid development of Information and Communication Technology (ICT). In UNESCO's 2005 Convention for the Protection and Promotion of the Diversity of Cultural Expressions, "Interculturality" is defined as "the existence and equitable interaction of diverse cultures and the possibility of generating shared cultural expressions through dialogue and mutual respect." ${ }^{2}$ However, interculturality has been seen as more than a sociological or anthropological concept. Its theological significance has also been explored in depth by prominent

\footnotetext{
* Corresponding author: Anthony Le Duc, Executive Director, Asian Research Center for Religion and Social Communication, St. John's University, Thailand. E-mail: leducsvd.arc@gmail.com
}

2 UNESCO, “Interculturality,” https://en.unesco.org/creativity/interculturality. 
Catholic theologians, such as, Anthony G Gittins and in various degrees by a whole host of writers from the Society of the Divine Word, especially in the Society's journal Verbum SVD as well as a various monographs. This essay intends to add to the discourse on interculturality, not from the perspective of theology or scriptural reflections, but with the consideration of the present social milieu characterized by tremendous advances in ICT. This paper raises the following questions: (1) What opportunities does the present digital milieu afford in the promotion of interculturality?; (2) What challenges to interculturality are presented by the present milieu?; (3) What is the proper understanding of interculturality in the modern digital context?; and (4) And how can interculturality be advanced within this context?

This essay proposes that although interculturality as a social and missiological ideal retains tremendous value in the modern digital milieu, its realization requires proper understanding of the present reality as well as the utilization of appropriate communicative strategies in order effectively maintain and promote the vision of interculturality. Without steps being taken to address the matters pertaining to ICT and interculturality, there is real fear that this paradigm which has gained popularity among social scientists as well as theologians in recent years will be extremely difficult to achieve.

\section{Defining Interculturality}

Interculturality has become an increasingly important concept in the Church in recent decades and speaks to the Church's ongoing cultural sensitivity in today's multicultural world. Indeed, due to globalization and international migration, societies are more culturally diverse than ever. Even in the rural villages of Northeastern Thailand, where in the past, there would only be Thai people known as Isan, there are now many foreigners who come to reside among them as spouses of Thai people or as people involved in different work (teaching English, manual laborers, missionaries, professional football players, tourists, etc.). Multiculturality is not only exclusive to big international cities, but can be found in towns and villages all around the world, and increasingly more so. The reality of this global changing of demographics calls for and provides opportunities for intercultural encounters as a part of everyday life of people everywhere. These encounters can be either positive or negative depending on the disposition and emotional state of the people involved in these encounters. They can be occasions for mutual respect, exchange and growth or events filled with misunderstanding, reinforced fear and hardened prejudices. At the community level, interaction between different cultural groups, especially immigrants, can take on different dynamics, such as assimilation, in which the minority group is assimilated into the dominant group to such an extent that part or all of the original diversity would be replaced by a more apparent homogeneity. For example, in Thailand, in the past ethnic Chinese and Vietnamese groups were all forced to adopt Thai names (both first and last) if they wished to "become" Thai. For many years, Vietnamese migrants in Thailand were not allowed to learn and speak Vietnamese; those who managed to learn how to read, write and speak the language had to do so secretly. These other attempts by the Thai government at that time were efforts to forge a common "Thai" identity in order to eliminate risks of social division and conflict.

Besides assimilation, another possibility that could take place is "integration," whereby the dominant group attempts to integrate or incorporate the minority group into society as equals. For many Vietnamese migrants in the United States, at the same time that they have adopted certain attitudes and ways of doing that reflect the local American culture, they also have retained many aspects of their native culture - eating habits, cultural celebrations and ways of addressing each other in conversation, etc. This is a more holistic approach dealing with cultural encounters than assimilation, which often suppresses the cultural aspects of the minority group. There are also other approaches dealing with diversity, which we will not go here for the sake of brevity.

Interculturality, however, is the way that social scientists as well as theologians (missiologists) have been turning in order to affirm the value of each culture in our multicultural world. Within the Catholic Church, the awareness of the value of interculturality could be seen in 1993 when Cardinal Joseph Ratzinger referred to the term in his address to the Asian bishops:

We should no longer speak of inculturation but of the meeting of cultures or "inter-culturality", to coin a new phrase. For inculturation presumes that a faith stripped of culture is transplanted into a religiously indifferent culture whereby two subjects, formally unknown to each other, meet and fuse. But such a notion is first of all artificial and unrealistic, for with the exception of modern technological civilization, there is no such thing as faith devoid of culture or culture devoid of faith. It is above all difficult to envision how two organisms, foreign to each other, should all of a sudden become a viable whole in a transplantation which stunts both of them. Only if all cultures are potentially universal and open to each other can inter-culturality lead to flourishing new forms. ${ }^{3}$

Joseph C. Ratzinger. (1993). Christ, Faith and the Challenge of Meeting Cultures, Address to the presidents of the Asian Bishops' Conferences and the Chairmen of their Doctrinal Commissions, Hongkong, March 2-5, p. 1. 
Interculturality has been perceived by some as a natural progression from the concept of inculturation, which dominated the latter part of the last century. According to Samuel Neceno Agcaracar, "Inculturation was basically deemed as a response to the call for decolonization and empowerment of the local Church, which was building up at the onset of the Vatican Council. It is therefore a paradigm that was born out of the need to respond to a contextual necessity." ${ }^{, 1}$ Dutch missiologist Franz Wijsen contends that modern Christian mission has been marked by three paradigms: the translation of Christianity into other cultures, resulting in the plantation of Euro-centric churches; inculturation of Christianity in other cultures, which dominated in the late $20^{\text {th }}$ century; and the coming interculturation of the church. ${ }^{5}$

In recent years, the term interculturality has been explained by multiple scholars, all of whom attempt to emphasize the dynamics involved in encounters by people from different cultures. Daniel Pietrzak defines "interculturality" as follows:

Interculturality, as it is increasingly understood, involves a challenging and probably never-ending process of development through interaction between members of different cultural groups. It certainly means more than mere "living in peace" with one another, "equal but separate." It cannot be reduced to some token cultural interaction, e.g., food, music, and similar folkloric expressions. Interculturality cannot be imposed by creating an artificial unity which suffocates all differences. Denial of the existence of differences does not foster unity; neither does defensive separatism. In effect, interculturation comes as the result of the integration of contributions from various cultural expressions to form something NEW without diminishing the value of each cultural component. ${ }^{6}$

We can see from this definition that there is an enhanced appreciation and emphasis on mutuality in cultural encounters. Interculturality rejects the notion that "we are all same" which can lead one group giving up its cultural identity for the sake of being same with the dominant group. Interculturality also rejects the assumption that every culture is essentially different, and common ground cannot be found among the various cultures. The inter-cultural model perceives that while cultures have differences, there are also cultural overlaps (analogy) that make groups both different and the same. According to Robert Kissala, "The use of intercultural (and its derivatives interculturality, interculturation) serves to emphasize and make more explicit the essential mutuality of the process of cultural interaction on both the personal and societal level. It also makes explicit goal of this process is neither assimilation nor the ghettoization of different people or cultures, but the appreciation and acceptance of similarities and differences."

The presentation of the concept interculturality thus far demonstrates that the paradigm goes beyond mere "internationality" or "multiculturality". Both of these concepts only describe situations or social facts rather than certain social processes. ${ }^{8}$ In other words, "internationality" refers to any situation involving people of different nationalities. For example, a religious community in Japan is considered an international community when there are 20 members coming from 6 different countries. I belong to the Society of the Divine Word, which is an international congregation. Therefore, wherever possible, we intentionally form international communities with members hailing from different countries. It is an SVD practice that has roots in the very first days of the Society's foundation. While this is not uncommon among international religious congregations, for the SVDs, this practice is not born out of chance or mere practicality, but represents an essential aspect of the SVD charism.

The term "multiculturality" is similar to its counterpart, except it serves to refer to culture as a point of distinction. In the community mentioned above, the 20 members might come from 6 different countries but 10 different cultures if some of the countries are culturally diverse so that two people might be of the same nationality, but of different cultures. At Lux Mundi National Major Seminary of Thailand, where I presently teach, all of my students are of Thai nationality. However, within each class, there could be five or six different cultures because the seminarians come from different ethnic groups (Hmong, Pakinyo, etc.). Even when the seminarians come from the same ethnic group, they are from different regions of the country with their own local cultures, food and dialect. Thus "culture" is much more fluid designation that nationality.

In this manner, the words "internationality" and "multiculturality" only state the fact about the national/cultural make-up of the community, but they do not reflect anything about the nature of the relationships among its members. In speaking about multiculturality, Gittins states:

4 Samuel, Neceno, Agcaracar. (2019). Interculturality in the Service of Communion: Exploring New Pathways of Mission, Logos Publications, Manila, 17.

5 Frans, Wijsen. (2006). Mission in a New Key: From Inculturation to Interculturation. in The Future of Missio Ad Gentes. SMA Generalate, Rome.

6 Daniel, Pietrzak. (2006). Interculturality and Internationality: A Utopia or a Constructive Tension for a Franciscan Missiology. Paper given at the International Missionary Congress OFM Conv, Cochin, India.

Robert, Kisala (2009). Formation for Intercultural Life and Mission. Verbum SVD, 50(39), 335.

8 Anthony, Gittins. (2006). Living Mission Interculturality: Faith, Culture and the Renewal of Praxis, xiii-xiv. Collegeville Liturgical Press, Minnesota. 
The word multicultural can apply to a de facto social reality without disclosing anything about the quality of relationships involved. Millions of people live in multicultural cities or neighborhoods, side by side with people from different cultures, but without ever trying to learn another language or encounter their neighbors in other than a perfuncionary or conventionally civic fashion. Multiculturalism has been described as "living together separately". 9

Nowadays, many people live in multicultural settings due to the circumstances of their lives more than due to actively seeking such an environment to settle. In Thailand's capital city of Bangkok and the surrounding provinces, there are millions of foreigners living and working in the bustling metropolis. There are many signs pointing to its internationality and multiculturality — food sold in shopping centers, languages heard on the street, the ethnic make-up of passengers riding the metro and so on-but few strong evidences that confirm interculturality. I have seen children of well-off foreigners working in Thailand, growing up in the country; however, because they go to international schools attended by socially affluent Thai and other foreigners where the language of instruction is English, these children never get to learn how to speak Thai. This is unfortunate, since young people can pick up a new language so easily, especially when they are already living in a country where the language is spoken.

In contrast to the two previous concepts, interculturality places emphasis not on a social reality but the dynamics taking place among people of different cultural backgrounds. It denotes mutual exchange between cultures that can lead to transformation and enrichment of those who participate in these interactions. ${ }^{10}$ A culturally diverse community characterized by interculturality will not simply exhibit co-existence, but instead, "interact with one another, learn and grow together, build relationships and become transformed, shaped, and molded from each other's experiences. The focus is not mere survival but more importantly, deep connections, interactions, mutual gifting, respect, and learning from one another." ${ }^{11}$ In other words, interculturality involves reciprocity, appreciation, and celebration of each other's cultures. It attempts to go beyond simply recognizing the uniqueness of a culture, and certainly beyond merely tolerating another culture, but making use of cultural resources - both of the subject as well as belonging to the person with whom the interaction takes place - as means towards transformation and growth. Thus, in our present globalized, multicultural world, it is simply not enough to extol internationality or multiculturality in community or society; what we must strive for is interculturality because this speaks not to the ethnic-cultural make-up of the group, but refers specifically to the quality of our relationships.

The adoption of interculturality as the paradigm for how we interact with one another as individuals and groups from different cultures hold tremendous implications for the pastoral work and the mission of the Church. As a globalized Church where we often live and work in cross-cultural and multicultural settings, how we relate to people from other cultures will determine the quality of our relationships and the life of the Church. It will affect how a parish community reacts to a foreign pastor and vice-versa. It will determine how a congregation reaches out to migrants who come to make the parish their new home. Interculturality will affect how members of a religious community relate to one another. Even in a country like Vietnam where most religious communities comprise of members from the same country, there is still multiculturality due to people coming from different parts of the country, which calls for interculturality in the way they interact with one another. Equally important is how the paradigm of interculturality will affect the mission work of the Church as it attempts to evangelize to people all around the world.

What has been communicated in the above paragraphs in a cursory manner is the importance of interculturality as a paradigm for human interactions in a multicultural church and world. This ideal that we strive for can be enhanced or hindered with the use of Information and Communication Technology (ICT). We will next examine the role of ICT in promoting or hampering interculturality in the digital milieu.

\section{Opportunities for Interculturality in the Digital Milieu}

The development of ICT has facilitated the promotion of interculturality in multiple ways, especially in the ability of ICT to eliminate many traditional external barriers to interculturality. These barriers include:

Space: The ability for intercultural communication is no longer obstructed by long distances between individuals. Whether in different cities, countries, or continents, individuals are able to get connected with the help of ICT. As of January $2020,59 \%$ of the world (4.54 billion people) were active internet users. ${ }^{12}$ Although there are still countries, such as, North Korea that register virtually no internet penetration among the general population, almost all countries around

\footnotetext{
9 Gittins, Living Mission Interculturality, xiv.

10 Lazar, Stanislaus., and Martin, Ueffing, eds. (2015). Intercultural Living, 1, xxiv. Sankt Agustin: Steyler Missions-wissenschaftliches Institut-ISPCK.

11 Ibid., xxiv-xxv.

12 https://www.statista.com/statistics/617136/digital-population-worldwide/
} 
the world are online to various degrees. Thus, nowadays, although people might find it difficult for various reasons to go beyond their province, city or country, this does not prevent them from connecting with family, friends and even strangers living in other parts of the world. For many children born in the digital era, even before they take their first steps, they are already communicating with someone who live far away.

Part of the work of the Asian Research Center for Religion and Social Communication (St. John's University, Thailand) where I presently the executive director, to organize annual international roundtable conferences. Our last conference was scheduled for March 9-12, 2020 in Bangkok, Thailand. However, in the days leading up to the conference, the pandemic was breaking out in multiple countries and also escalating in Thailand. As a result, a number of conference participants, including those from India, the Philippines and Taiwan were not able to attend the event in person due to travel restrictions enforced either by the country or by the institution having auspices over the scholar. Fortunately, some were still able to travel while others were already in the country. After much discussion with the board of ARC and the leadership of St. Louis College where the conference was to take place, we decided to go ahead with the roundtable as planned. Those who could not physically come to Bangkok were offered the opportunity to present their papers through Google Meet. As a result, we had a "hybrid" conference where half of the participants presented their papers in person while the other half participated online. For conferences and events that took place later on in the pandemic, it was almost online. "Webinar" became the familiar term referring to seminars and conferences that took place in cyberspace. Thus, despite being physically separated due to the pandemic, meetings, discussions and encounters continued to take place and thanks to the help of ICT.

Time: Because online connection is virtually constant, and messages sent via chat applications can be received almost instantaneously, opportunity for intercultural communication is exponentially increased compared with pre-Web 4.0 era. No longer do we have to wait for days or weeks for correspondences to reach our hands. Because so many of the mobile gadgets are now internet-enabled (phones, watches, ipads, etc.), it is becoming increasingly difficult to "miss" incoming calls and messages if these things are not intentionally turned off. Communication can be carried out immediately in most instances, and "lost" emails and messages can usually be retrieved if they have not been completely deleted out of the system.

Economic Means: In the past, if a trip outside of one's hometown or country was a big investment of time and money for many people around the world, the availability of ICT even in some of the remotest places on earth means that there are plenty of opportunity for being exposed to and learning about other cultures without even having to leave one's own home. The cost of ICT gadgets being greatly reduced in recent years has also helped to facilitate intercultural exchange. In many developing countries, the rate of internet penetration is higher than that of urbanization. Southeast Asia is a case in point. After Thomas Edison invented electricity in 1879, some streets in New York City began to enjoy the fruits of this new technology in 1882, with the first large scale central station installed on Pearl Street to 85 customers. After this life changing invention and many other subsequent technological advances, the American people had to wait another 112 years before they were able to have access to the internet through the first commercialized web browser, Netscape Navigator released in 1994. Of course, internet technology had already been in development for decades, but it was not until 1994 that the technology was truly available to the general public. During that span of over 100 years, the United States went through many periods of development and managed to achieve 50\% urbanization in $1920 .{ }^{13}$ Compared to the United States, Southeast Asia has seen a much lower pace of technological development. In some parts of the region, such as, secluded highlands and islands, there is still no electricity for everyday use. People in many places are still using firewood for cooking and are still traveling on dirt roads. In fact, Southeast Asia was estimated to achieve 50\% urbanization only in 2019, 99 years after the United States. ${ }^{14}$ Despite the huge discrepancy between the United States and Southeast Asia in terms of history of technological advancement, the region is quickly getting on the train of digital development.

With a total population of nearly 700 million as of August $2020,{ }^{15}$ Southeast Asia is the third most populous geographical region in the world, only behind South and East Asia. Despite the fact that urbanization in Southeast Asia is only about $50 \%$, internet penetration has already reached nearly $66 \%$ at the beginning of $2020{ }^{16}$ with double-digit growth in most segments and most countries of the region. ${ }^{17}$ Brunei leads the region in internet penetration at

13 US Census, “Urban and Rural Areas,” https://www.census.gov/history/www/programs/geography/urban_and_rural_areas.html\#: : text $=\% 22$ Urban $\% 22 \% 20$ was $\% 20$ defined $\% 20$ as $\% 20$ including,population $\% 20$ was $\% 20$ defined $\% 20$ as $\% 20$ urban.

14 "Southeast Asia and Sustainable Urbanization," Global Asia, https://www.globalasia.org/v9no3/feature/southeast-asia-and-sustainableurbanization_bharat-dahiya\#: :text=Estimates\%20 show\%20that\%20Southeast\%20Asia,urban\%20population\%20to\%20330\%2 0million.\&text=Between\%201950\%20and\%202014\%2C\%20the,26\%20million\%20to\%20294\%20million.

15 "Southeast Asian Population," Worldometers, http://www.worldometers.info/world-population/south-eastern-asia-population/

16 We Are Social, January 2020, https://wearesocial.com/blog/2020/01/digital-2020-3-8-billion-people-use-social-media

17 Atzlan Othman, "Facebook most popular social mediate platform in the Sultanate," Borneo Bulletin. https://borneobulletin.com.bn/ facebook-most-popular-social-media-platform-in-the-sultanate/, (May 19, 2018). 
95\%. ${ }^{18}$ Digital development in the region, however, is not even. While the regional internet penetration is higher than the global average (57\%), several countries in the region fall quite far below the global average, with Timor Leste, ${ }^{19} \mathrm{Myanmar}^{20}$ and Laos, ${ }^{21}$ having internet penetration at only 39\%, 41\%, and 43\%, respectively. Nonetheless, the growth rate across the region is high, and with so many Southeast Asians getting online, the region presents itself as the third-largest market globally. According to experts, the internet economy is expected to reach $\$ 300$ bn by $2025 .{ }^{22}$

Prohibitive Social and Cultural Norms: In the physical environment, people are often limited by social and cultural norms governing whom they can meet and talk. In some cultures, the taboos of engaging in conversation or staying near someone from outside of one's culture, caste or socio-economic group are strictly enforced in the analog environment. In some countries, some cultural practices isolate people from others altogether at various times. In parts of India for example, girls and women of the Gond and Madiya ethnic groups undergoing menstruation are forced to stay in a hut outside of the village for five days, which prevents them from having any interaction with other people around them. ${ }^{23}$ Banished in poorly built huts on the edge of the forest, being exposed to bad weather and dangerous animals, these experiences are both isolating and traumatizing. Social separation due to extreme customs, such as, banishment during menstruation or norms governing how people of different gender and economic classes interact in public can be overcome with the help of ICT. The digital environment eliminates many of these obstacles because one's use of ICT can be carried out in private spaces or in a manner that minimizes attracting the attention of prying eyes and controlling authorities ever ready to warn against these kinds of activities. For many people around the world, mobile phones usually come with social network applications already installed and can be used easily to connect with other people online. It has been often the case that despite many people not knowing how to send and receive emails, they are skillful at using social network platforms, such as, Facebook, YouTube and LINE.

Global Mindset: The external barriers of space, time, economic means, and prohibitive social and cultural norms are, moreover, supported by the process of globalization and the development of a global mindset that draws individuals and groups towards a more interconnected reality. This reality can be reflected in consumption of information (news, movies, pictures), consumption of material goods (food, clothing, electronic gadgets), and daily activities (taking selfies, updating one's status on one's preferred social media app, checking in to different places, etc.). Besides sharing similar superficial activities mentioned above, a global mindset could be displayed in how people react to different issues that not only concern one's local situation but that of the entire world. Swedish teenager Greta Thunberg, who managed to appear before the United Nations and was honored by the American magazine TIME as "Person of the Year" for 2019 exemplifies the global mindset. Her activism aimed towards promoting ecological awareness and international policy change on behalf of the ecology has garnered worldwide acclaim (as well as disdain among some individuals) because her efforts have been publicized through modern means of ICT. At the same time, any person, whether young or old, can easily develop this global mentality without necessarily having to travel the world. A young person in Myanmar does not have to take a trip to the Amazon to know that the forest is being destroyed by logging and cattle farming. An inhabitant of Zimbabwe can also understand how China is harming the environment with its massive factories and dams without having ever setting foot in China, or meeting any Chinese for that matter. ICT enable us to be global citizens and have a sense of the earth being everyone's common home that must be assiduously cared for.

\section{Challenges to Interculturality in the Digital Milieu}

Despite the fact that the development of ICT presents many opportunities for interculturality, there are obstacles brought about by our increasing dependence on ICT in everyday life. Obstacles include the following:

Non-embodied Interconnectedness: ICT emphasizes non-embodied interconnectedness and therefore limits the experience of interculturality. Interculturality is first and foremost experience of mutual communicative interaction. Communication is done not only through words being pronounced mechanically (as can be heard in computer programs that can read texts), but also accompanied with physical gestures (hand gesticulation, body movements, blinking of the eye, frowning of the forehead, etc.) and actions (handshaking, bowing, standing up, kneeling, etc.) taking place in a physical setting.

\footnotetext{
18 "Digital 2020: Brunei," (18 February 2020), https://datareportal.com/reports/digital-2020-brunei-darussalam\#: :text=There\%20were\% $20413.0 \% 20$ thousand\%20internet,at\%2095\%25\%20in\%20January\%202020.

19 “Digital 2020: Timor Leste," Datareportal (18 February 2020), https://datareportal.com/reports/digital-2020-timor-leste

20 “Digital 2020: Myanmar," Datareportal (18 February 2020), https://datareportal.com/reports/digital-2020-myanmar

21 “Digital 2020: Laos," Datareportal (18 February 2020), https://datareportal.com/reports/digital-2020-laos

22 “Southeast Asia's internet economy to hit $\$ 300$ billion by 2025: report," Reuters (3 October 2019), https://www.reuters.com/article/ us - southeast-asia-internet/southeast-asias-internet-economy-to-hit-100-bi11ion-this-year-reportidUSKBN1WI07X\#: :text=Southeast\%20Asia's\%20internet\%20economy\%20to\%20hit\%20\%24300\%20billion\%20by\%202025\%3A\%20report,Aradhana\%20Aravindan\&text=SINGAPORE\%20(Reuters)\%20\%2D\%20Southeast\%20Asia's,industry\%20report\%20said\%20on\%20Thursday.

23 https://www.theguardian.com/global-development/2015/dec/22/india-menstruation-periods-gaokor-women-isolated
} 
When greeting one another, Thai people not only say the word of greeting "Sawatdee" but also place both of their palms together in front of their chest as a gesture of respect called "wai". The exact placement in front of the chest (higher or lower) depends on the status or age of the person one is greeting. How people "wai" each other may also be affected by the physical setting that they are in - at home, at a bar, at a temple, or at work. The cultural element is also displayed in one's accent and intonation. All these particular characteristics add nuances, richness and meaning to the communicative event. Communicating through text messages on the screen eliminates access to information that would be deciphered from noticing details about one's voice and physical gestures. As Pope Francis observes in the encyclical Fratelli Tutti, digitally mediated communication and relationships "lack the physical gestures, facial expressions, moments of silence, body language and even the smells, the trembling of hands, the blushes and perspiration that speak to us and are a part of human communication." ${ }^{24}$ In other words, due to the elimination of numerous culturally informative elements in non-embodied communication, the potential for interculturality in digitally mediated communication may be greatly reduced, especially when the non-embodied communication is not accompanied by video images.

Unequal Power: Interculturality is negatively affected by the dominance of certain languages on the internet. Statistics indicate that the three languages most used on the internet by share of internet users are: English (25.9\%), Chinese (19.4\%), and Spanish (7.9\%). ${ }^{25}$ However, in terms of language popularity, of the top 10 million websites on the World Wide Web, 60.6\% are in English. ${ }^{26}$ Therefore, if one did not speak English, one would be virtually shut off from accessing a great deal of valuable information on the web. On the other hand, since English is the dominant language online both in terms of number of users and popularity of websites, people everywhere feel compelled to study and know English in order to access information and interact with others online. While having a few common languages as medium for communication connects more people around the world together, it also means that many other languages remain unknown and severely underrepresented in cyberspace. The use of a few dominant languages also means that the cultures which are home to those languages will be more prominent while other cultures will remain obscure.

The dominance of the "internet culture": ICT potentially obscures the individual cultures because the internet in fact has its own culture. Admittedly, diversity exists on the internet as much as in real life, and it would be misleading to assert a uniform internet culture. However, one can speak of a "popular internet culture" characterized by its own language patterns, style of communication, and even special signs and symbols that stand for particular ideas. When using the internet, individuals become acquainted with these signs and symbols of communication, many of which have been invented by some software engineer working for a giant tech company, such as, Facebook, Google and Tencent. People who use the internet are subsequently inculcated into this internet culture and this particular way of communicating. Whether one comes from Africa or from Asia, using Facebook exposes him/her to a set of emojis developed by Facebook to represent certain emotional state or reactions. Those emojis, usually cartoonish in nature, are used by teenagers as much as they are used by an older person. Cultural and generational distinctions are erased by a set of signs and symbols used by all users regardless of culture, religion, gender or age. Emojis with their cute and overly exaggerated expression of emotions make people come across as extremely expressive and demonstrative in their expression of "joy" and "sorrow," while in fact, by personality or by cultural proclivities, they may not be so emotionally expressive in real life. When people are governed by the internet culture in their interactions with one another, the individual cultural traits cannot be put on display in the intercultural interaction, thus diminishing opportunities for mutual exposure and learning from each other's specific cultures. What is more disturbing is that some of the exaggerated ways of communicating online is being transferred into real life communication; for example people in all parts of the world making the "like" gesture or the "mini heart" gesture while taking photos. Apparently, in many ways, instead of internet becoming diverse from having a plurality of people going online, the internet is in fact making the real world looking more and more like it.

The Danger of Fake News: Interculturality faces great challenges in the digital era due to the abundance of fake news centered on cultures and religions. In this age, individuals can be both consumers as well as producers of news and entertainment, anyone could distribute information to the public in seconds without having to go through any system of checks for value and credibility.

Much of the checking that takes place is after the information has already been publicized and has already made it to millions of individuals. And there is no guarantee that those checks ever reach the people who have already been exposed to fake news. With the unimaginable rate of information production taking place nowadays, it is impossible to control fake news and disinformation, which not only concerns cultures and religions but seemingly every aspect of

\footnotetext{
${ }^{24}$ Pope Francis, Fratelli Tutti, no. 43.

${ }^{25}$ https://en.wikipedia.org/wiki/Languages_used_on_the_Internet

26 Ibid.
} 
life. Fake news and disinformation about cultures is damaging because it not only can propagate false perceptions of other cultures, but also reinforce already deep-seated prejudices about other cultures and peoples. Many people might not have any direct experience about other cultures in their everyday life, but have perceptions about them through what they read online or through news clips. That is why it is extremely damaging when prominent political or religious leaders make disparaging remarks about a particular group of people. This negative sentiment would be propagated around the world in matters of minutes and seconds.

The Harm from Algorithms: Interculturality further faces challenges from ICT development in the form of algorithms that helps to deliver personalized content to users of the internet, especially social media applications. The goal of personalized content is that everyone gets access to information and materials that are of interest to them. The intention on the surface is an honorable one. After all, there is so much information and content out there, and one does not want to waste time sorting through all sorts of trash before finding something that one is interested in. Technology companies develop algorithms in order to help to deliver the content that you are interested in a more expedient manner. If watching clips of cute animals and babies is your hobby, the algorithm knows that and gives you more of what you like. Amazon's algorithm follows your shopping habit and suggests products that it thinks you would like to have. Kindle suggests books that you might want to read based on what you have bought in the past. Netflix does the same thing with the movies you watch on its service.

On a personal basis, these algorithms are extremely convenient. However, from the point of interculturality, algorithms are dangerous. Unless one actively searches for content concerning cultures, religions and interculturality, your internet experience will basically resolve around things of interest to you, which may or may not expose you to various cultures. On the other hand, if you show an interest in matters that lean towards anti-culture, anti-religion, etc., the computer algorithms will take note of these interests and deliver to you more of what you like. You might go from a slight bigot to a hard-core bigot by consuming more and more of the same sort of information that reinforces a certain perspective. The tendency to expose oneself to only one particular type of information can easily lead to enclavism and polarization. On a systemic level, this negative inclination which is further aided by computer algorithms is extremely detrimental to interculturality.

\section{Promoting Interculturality in the Digital Milieu}

Interculturality is a paradigm worth promoting for the sake of personal transformation and building global peace and harmony. However, confronting the many potential dangers to interculturality presented by ICT, efforts must be actively implemented in order to take advantage of the positive aspects of ICT and limit the negative impact to interculturality coming from it. The final part of this essay presents some ideas regarding how the Church and individuals must take charge of how ICT is used in everyday life and in service of the evangelizing mission of the Church.

\subsection{Digital Literacy}

As ICT has an important role in interculturality, the informed and prudent use of ICT is essential to promoting this social and missiological paradigm. Digital literacy is needed in order to:

Distinguish authentic news and information from fake news, misinformation and disinformation. Fake news has been around as long as there have been human society, so this is not an invention of the digital age. However, what is unique to the digital age is the quantity of fake news, misinformation and disinformation that is produced every second around the world. With the aid of ICT, this type of information can be produced, disseminated and shared in an extremely fast manner. Moreover, with the aid of ICT, this kind of information can be packaged and presented in such a way that can get people to believe that what is being said is true, believable and should be shared. Technology is helping to make "deep fake" videos of famous people speaking look so real that an average person unequipped with technological training would not be able to tell the difference. Thus, in order to stay away from buying into fake news, misinformation and disinformation that instigate intercultural and interreligious conflict, there must be some digital education to assist individuals in making distinctions between what is authentic information and what is divisive and destructive. When people are able to distinguish between valuable information and untrue and destructive information, they are less likely to share and disseminate content that is detrimental to social peace and harmony.

Make critical evaluations of religious and cultural perspectives found on various websites. The internet is filled with perspectives on all kinds of matters from the most trivial and mundane to the most profound issues in human life. In the present context where everyone and anyone can be producers and curators of information, all have the potential to be influencers by presenting their personal views on politics, religion, culture, and so on. Unfortunately, more often 
than not, people with cursory knowledge of a particular issue end up presenting very strong views to persuade others. Through the ability to make an interesting video, their fame, their look, or their skillful use of language and technological techniques, some people can attract massive followings and exert great influence on their audience despite not being deeply informed on the subject matter which they are addressing. Therefore, it is important that each person when listening to a particular cultural or religious perspective raises the necessary critical questions to evaluate whether what is being said is credible and beneficial towards interculturality and interreligious harmony. While the internet is a forum where anyone can express themselves, it is the responsibility of the consumer of content to make informed judgments about what to view and how to react to what he or she sees.

Overcome being led into polarization and extremism. It is indeed convenient to have computer algorithms help to "personalize" the online content for each individual user. Algorithms attempt to save the consumer time by eliminating all the things that they think the user would not be interested in. While this has some advantages, especially when a bald man does not have to repeatedly see advertisements for shampoo, over-dependence on algorithms greatly increases the risk for social and political polarization and extremism. If a person who has some latent prejudices towards Islam accesses content that affirms these prejudices, then get continually served with more such content because computer algorithms see that this is what he likes, what was initially inconsequential prejudices may turn into full-fledged Islamophobia exhibited in hate speech and other anti-Muslim actions. As people enjoy accessing content that affirms their own prejudices and interests, algorithms indeed support prurient, banal and self-centered tendencies within us. Thus digital education needs to aim at helping individuals understand the working of computer algorithms and other means pulling individuals down the path of fundamentalism, extremism and polarization. Without knowledge of the working of ICT, self-awareness and informed use of ICT, we set ourselves up for going down extreme paths that are counterproductive to dialogue, mutual cooperation, fraternity and interculturality.

Creating opportunities for serendipitous encounters. Some of the most rewarding experiences in life come as unplanned events - a birthday surprise, an unexpected call from an old friend, a sudden proposal for collaboration from a colleague, a chance encounter with a person, an animal or a natural scenery. While serendipitous encounters are countless in our lives, and most may not affect our lives in any consequential way, others can be out-right life-changing. All of us can perhaps recall at least a few such events in our lives. Although by definition, serendipity is supposed to be "serendipitous," meaning whatever happens is "unplanned," "unanticipated," "accidental;" nevertheless, serendipity can only happen when we live our lives in such a way that facilitates greater opportunities for serendipitous encounters. One who spends all his time in the house, not willing to leave except to get groceries will likely decrease his odds for experiencing serendipitous encounters. One who only engages with a certain kind of content online will definitely decrease the chance for exposure to other views and perspectives. Therefore, in order to create opportunities for more unexpected, but potentially rewarding and life-changing encounters in our life, even in digital spaces, we must be willing to take the conscientious steps into unfamiliar spaces, to read and listen to new voices, to be open to different experiences, and to be willing to share our own stories with others. Digital literacy is necessary in order to help individuals know how to navigate the digital spaces in order to enrich this online experience and to diversify the kind of encounters that they can have in cyberspace.

\subsection{Interreligious Dialogue}

Religion is a part of culture. In many countries around the world, people do not refer to their spiritual beliefs and practices as religion but as "culture" or "way of life." In Thailand for example, there does not seem to be any real distinction between Buddhism as a religion and Buddhism as a culture. The two are inextricably intertwined in the everyday life of the people, and any attempt to separate the two would be rather artificial. Therefore, we cannot speak about interculturality without mentioning interreligious dialogue. Interreligious dialogue needs to take place both online and offline at all levels of the Church. Pope Francis' apostolic visit to Iraq in March 2021 was an excellent example of how world religious leaders use their positions to engage in interreligious dialogue. In the speech at the Presidential Palace, welcoming Pope Francis, Iraqi president Barham Salih said, "We must continue efforts to combat extremist thought, and stamp out the roots of terrorism. We need to ensure the victory of the ideas of coexistence and diversity that are the pride of our nations, and turn them into a source of strength and cohesion. For establishing these beliefs has become an imperative in our world today, and it is the most precious gift that we can give to the future of our generations to come." 27 President Salih acknowledged that Christians in Iraq as well as neighboring countries "are the indigenous people of this land and its salt." The fact that Christians have been forced to migrate to other countries for survival due to various crises "will have dire consequences for the concepts of pluralism and tolerance. It will also have dire consequences for

\footnotetext{
${ }^{27}$ https://www.thenationalnews.com/mena/iraq/pope-in-iraq-barham-salih-s-welcome-speech-in-full-1.1178379
} 
the ability of the countries of the region themselves to live together. For it is impossible to imagine the East without Christians." Indeed, it is as important for Christians in Iraq and other Muslim majority countries to hear these words of affirmation from a Muslim political leader as for Muslims hearing Pope Francis declare, "May God grant that we journey together as brothers and sisters in 'the firm conviction that authentic teachings of religions invite us to remain rooted in the values of peace... mutual understanding, human fraternity and harmonious coexistence"' (Document on Human Fraternity, Abu Dhabi, February 4, 2019).

The interreligious encounters that took place in physical spaces in the age of the internet and social media did not remain confined to the analog sphere, but was widely broadcasted on different communication media—radio, television, and myriad internet platforms. When people around the world-Muslims, Christians and anyone else who tuned in could see Pope Francis and Muslim leaders speak amiably to one another with mutual respect and trust, emphasizing the common roots of Christianity and Islam, extolling the virtues of interreligious peace and cooperation, surely the impact on the viewers and listeners cannot be underestimated. When the Pope met the Grand Ayatollah Sayyid Ali al-Husayni al-Sistani, one of the leading spiritual leaders of Iraq's Shia Muslims, even though the meeting was behind closed doors, images of the two faith leaders sitting closely together were made available to the public. Despite not having access to the content of the conversation, just the optics of these two humble and deeply spiritual leaders sitting side by side created strong impressions in the mind of Muslim and Christian adherents all around the world. According to a statement from the Holy See Press Office, during the courtesy visit, which lasted about forty-five minutes, "the Holy Father stressed the importance of cooperation and friendship between religious communities for contributing-through the cultivation of mutual respect and dialogue — to the good of Iraq, the region and the entire human family." ${ }^{28}$ What is being done by the highest leader in the Church, however, has to be replicated on a smaller scale by local Church leaders and Christians around the world. Indeed, the mission of the Church can never go forward without every sector of the Church taking seriously the task of interreligious dialogue.

Interreligious dialogue can also be carried out online in various forums where discussions about religion take place. Unfortunately, while there are much discussing and commenting on religious matters taking place in the digital sphere, much of it is expressions of attack, unfounded assumptions, prejudices, sarcasm, obscenity and so on that are meant to instigate interpersonal and interreligious conflict and division rather than dialogue and mutual understanding. At a time when the internet is full of individuals paid by governments and organizations to represent them in online forums and counter attacks against them, the Church does not have anything in this manner. The Chinese government has been reported to recruit countless individuals to be part of what has been called the " 50 Cent Army" to serve as commentators on internet forums to manipulate public opinion and disseminate disinformation for the benefit of the governing Chinese Communist Party. Although the Church should not act like the Chinese or Russian governments, the tactics by them and numerous governments around the world demonstrate that having active online representation is a necessity in the digital milieu. The Church also needs its representatives online in a systematic and pro-active manner in order to counter misrepresentations about the teachings of the Church, to counter forces that aim to creative division in the Church and interreligious conflict. This online representation would serve as a needed extension of what the Church is doing offline in many settings from the local parish to the activities taking place at the Vatican. Without this online endeavor, there is real danger that the efforts taken by the Church in the physical sphere alone will be insufficient to promote fraternity and interculturality.

\subsection{Resistance to the Technocratic Paradigm}

In the encyclical Laudato Si, Pope Francis critiques what he calls the "technocratic paradigm" being widely employed for social and economic development with great negative consequences to human and natural ecology. Pope Francis characterizes the technocratic paradigm as an "undifferentiated and one-dimensional paradigm" that aims for "indefinite or infinite growth" by mastering, possessing, controlling, manipulating and transforming others. ${ }^{29}$ "It is based on the lie that there is an infinite supply of the earth's goods, and this leads to the planet being squeezed dry beyond every limit." ${ }^{30}$ Unfortunately, technology has become so ingrained in human life that "the idea of promoting a different cultural paradigm and employing technology as a mere instrument is nowadays inconceivable. The technological paradigm has become so dominant that it would be difficult to do without its resources and even more difficult to utilize them without being dominated by their internal logic." ${ }^{31}$ Nevertheless, Pope Francis insists that there must be a new outlook, a new approach towards life, education, and policy making, and new spirituality in order to counter the increasing domination

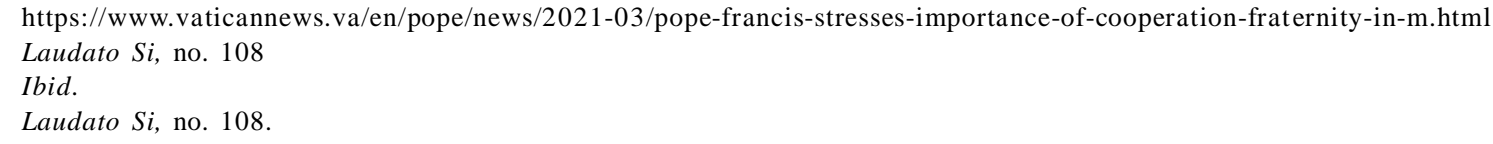


of the technocratic paradigm. Although technology can and must be employed to solve various social and environmental dilemmas plaguing the world, technology cannot be the cure when it is oftentimes the cause of the problem in the first place. Pope Francis asserts, "To seek only a technical remedy to each environmental problem which comes up is to separate what is in reality interconnected and to mask the true and deepest problems of the global system."

Therefore, what is needed is not a technocratic approach towards solving the social problems but one that supports an "integral ecology and full development of humanity." ${ }^{32}$ An integral ecology that takes into account authentic human development and the common good ultimately affects every dimension of human life - economic, social, political, and spiritual. Social, environmental as well as other types of problems appear when there is an imbalance in the "human ecology." As Pope Francis observes, Many people today sense a profound imbalance which drives them to frenetic activity and makes them feel busy, in a constant hurry which in turn leads them to ride rough-shod over everything around them. This too affects how they treat the environment. An integral ecology includes taking time to recover a serene harmony with creation, reflecting on our lifestyle and our ideals, and contemplating the Creator who lives among us and surrounds us. ${ }^{33}$

In a similar manner, media critics have pointed out that Silicon Valley based tech companies such as Google and Facebook often present themselves and their philosophy in a manner that could be comparable to a religious institution. Kevin Healey and Robert H. Woods Jr. in their book Ethics and Religion in the Age of Social Media: Digital Proverbs for Responsible Citizens (2019) characterize the tech company worldviews as that of techno-centrism, data fundamentalism and informationism with their own sort of catechism. The main tenets of Silicon Valley catechism include: (1) Information is wisdom; (2) Transparency is authenticity; (3) Convergence is integrity; (4) Processing is judgment; and (5) Storage is memory. ${ }^{34}$ Healey and Woods refute these catechisms and points out how Silicon Valley and its influential inhabitants attempt to misrepresent these aspects of the tech culture as ethical virtues, which they decidedly are not. Instead of being virtues, they can be extremely harmful to human flourishing and well-being. Quoting the Catholic theologian and French sociologist Jacques Ellul, the authors write, "Excessive data do not enlighten the reader or the listener; they drown him." Information alone, argue the authors, is a far cry from wisdom. Information is related to wisdom, but wisdom is not just simply having access to unlimited data, but the ability to make use of information with prudence and contributes to the common good. In the same manner, tech companies call for transparency and equate it with authenticity. Transparency, according to them, means sharing more about yourself online to family and total strangers, and this somehow helps one to realize more fully one's authentic self. The authors dispute the idea that informational transparency serves as the basis for an authentic life. A degree of privacy and secrecy, they argue, is conducive to maintaining agency and is necessary for authentic development of individuals and organizations. They point out the irony that while Mark Zuckerberg calls for more sharing online and more transparency, he himself purchased four homes in his neighborhood in order to ensure that developers would not encroach on his privacy.

Others critical of the way tech companies operate also accuse them and their software engineers of hubris and harboring self-serving agendas. This is seen in how tech companies promote algorithmic processing of data as being more efficient and better than human judgment. People are made to believe that raw data is objective and has our best interests in mind, and platforms like Google, Facebook, Instagram and Twitter seem to cater to our personal interests and values through "personalized" content. In reality, the perceptive user will often notice that she has been pigeonholed into certain identity categories that lie beyond her ability to control. The user finds herself having to endure an identity that has been constructed by others for their own benefit. When going online to these platforms, we are sorted into categories with labels that would be beneficial to companies that need to target particular kinds of customers. Even when the algorithm seems to be catering to our needs, it is in fact pandering to our prejudices, our hidden fears and desires. At the same time that algorithms cater to our biases, they themselves also reflect the biases of the software engineers who knowingly or unknowingly code them into their programs. This is especially problematic because diversity is not a strong feature of tech companies located in Silicon Valley.

In order to overcome the technocratic paradigm which promotes blind trust in technology, according to Pope Francis, we "need to slow down and look at reality in a different way, to appropriate the positive and sustainable progress which has been made, but also to recover the values and the great goals swept away by our unrestrained delusions of grandeur." ${ }^{35}$ Although we will never revert to pre-ICT days, "There needs to be a distinctive way of looking at things, a way of thinking, policies, an educational program, a lifestyle and a spirituality which together generate

32 Laudato $S i$, no. 62.

33 Laudato $\mathrm{Si}$, no. 225.

34 Kevin Healey and Robert H. Woods Jr., Ethics and Religion in the Age of Social Media: Digital Proverbs for Responsible Citizens (New York, NY: Routledge, 2019).

35 Laudato Si, no. 114 
resistance to the assault of the technocratic paradigm. ${ }^{36}$ Part of the solution is to advocate and build a "digital humanism". This requires traditional institutions in politics, business and commerce education, and civics and professional organizations to exercise their prophetic imagination to institute change. When groups and individuals such as social and religious leaders reclaim their traditional influential power, they can counter the present techno-centric tides in order to maintain human authenticity amid the increasingly digital milieu.

In the face of this digital tide that threatens to distort traditional ethical and spiritual values, a "digital humanism" can help to: promote prudent use of ICT aimed at the common good; promote integral development in order to achieve true human agency and authenticity; promote faith in God and not faith in technology; prioritizes human dignity over profit and efficiency; and promote a dynamic interculturality rather than a mono-technical culture.

\section{Conclusion}

At the same time that interculturality has become a paradigm recognized by both social scientists and theologians, especially for the evangelizing mission of the Church, the insights contained in this paradigm may be difficult to realize in the digital age dominated by digital information and computer technology, buttressed by the technocratic paradigm. Admittedly, ICT has the potential to support the interculturality paradigm in very dramatic ways because it eliminates multiple barriers to interculturality-time, space, and socio-economic-cultural-political obstacles. Nevertheless, while one set of challenges is reduced, other potentially even more harmful and debilitating challenges arise-those that cause extremism, polarization, and division. Confronting these two opposite possibilities, the Church needs to continue to exercise its prophetic voice through various means available to it in order to call awareness to the values and ways of being and doing that promote interculturality. Only then, can we hope to see the ideals espoused by interculturality realized in the life of the individuals, communities and the world.

\footnotetext{
36 Laudato Si, no. 111.
} 